\title{
Root dentine thickness of danger zone in mesial roots of mandibular first molars
}

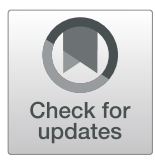

\author{
Guangchao Zhou ${ }^{1,2 \dagger}$, Diya Leng ${ }^{1,2,3 \dagger}$, Mingming Li $i^{1,2,3}$, Yang Zhou ${ }^{1,2,3}$, Cuifeng Zhang ${ }^{1,2,3}$, Chao Sun ${ }^{1,2}$ and \\ Daming $\mathrm{Wu}^{1,2,3^{*}}$ (D)
}

\begin{abstract}
Background: Better understanding of the danger zone anatomy in mesial roots (MRs) of mandibular first molars (MFMs) may serve to decrease the risk of mishaps. This study aimed to measure the minimal distal dentine thicknesses of danger zone in MRs of MFMs in a native Chinese population using cone-beam computed tomography $(\mathrm{CBCT})$.

Methods: CBCT images of 1792 MFMs from 898 Chinese patients were analyzed. The minimal distal dentine thicknesses of the mesiobuccal (MB) and mesiolingual (ML) canals below the furcation 1, 2, 3, 4, $5 \mathrm{~mm}$ were measured. The association between the minimal distal dentine thicknesses and the root lengths, patient's age and gender, side were assessed.

Results: The minimal distal dentine thicknesses of MB and ML canals are located $3 \sim 4 \mathrm{~mm}$ below the furcation for both men and women. There are no differences between MB and ML canals, while the minimal distal dentine thicknesses of $\mathrm{MB}$ and $\mathrm{ML}$ canals were higher in men than women $(P<0.05)$, except at 1 and $3 \mathrm{~mm}$ of $\mathrm{ML}$ canals $(P>0.05)$. The minimal distal dentine thicknesses of MB and ML canals increased with age in both men and women at each location $(P<0.05)$. The minimum distal dentine thickness at every location were significantly different between long teeth and short teeth both in men and women $(P<0.05)$, with short teeth having the smallest mean values. There are no significant differences between two sides $(P>0.05)$.
\end{abstract}

Conclusions: The minimal distal dentine thicknesses of MRs in MSMs have close correlation with root length, patient's age and gender.

Keywords: Cone-beam computed tomography, Danger zone, Mandibular first molars, Mesial roots

\section{Background}

The mandibular first molars (MFMs) are the first posterior teeth erupt, they are more likely to be affected by lesion. MFMs seem to be the most frequent endodontically treated teeth, with an incidence as high as $17.0 \%$ [1]. They usually have 2 or 3 roots, with 2 or 3 canals in the mesial roots (MRs) [2]. Approximately $2 \mathrm{~mm}$ below the furcation of MFMs, the MRs have a greater concavity in distal surface and the thickness of dentine is

\footnotetext{
* Correspondence: wdming@njmu.edu.cn

${ }^{\dagger}$ Guangchao Zhou and Diya Leng contributed equally to this work.

${ }^{1}$ Jiangsu Key Laboratory of Oral Diseases, Nanjing Medical University, 136 Hanzhong Road, Nanjing 210029, People's Republic of China

${ }^{2}$ Department of Radiology, the Affiliated Stomatological Hospital of Nanjing Medical University, 136 Hanzhong Road, Nanjing 210029, People's Republic of China

Full list of author information is available at the end of the article
}

limited [3]. They are described as danger zones because there are more prone to strip perforation during root canal shaping and post space preparation procedures [4, 5]. In addition, the excessive structure loss in danger zones may also lead to root fracture under functional loads. These complications make the root canal system connecting with its support tissue, promoting the spread of bacteria and inflammatory reactions that can hinder the success of endodontic treatment [6]. Therefore, the knowledge of the root and canal morphology and dentin thickness in the danger zones of MFMs is essential for preventing endodontic mishaps leading to failure [7].

Many studies have investigated the danger zone of the MRs of MFMs in different human races, such as Italy [3], Spain [8], Brazil [5, 9], USA [10-12] and Asian origin $[7,13,14]$. In general, the danger zone is located 4 
to $6 \mathrm{~mm}$ below the canal chamber orifice [10], and the minimum distal dentin thickness was located between 1 and $2 \mathrm{~mm}$ under the furcation. The mean thickness of dentine $2 \mathrm{~mm}$ below the furcation in MRs of mandibular molars ranges from 0.78 to $1.27 \mathrm{~mm}[5,7-14]$. In addition, there are some reports correlating these measurements with root length of the teeth. Sauáia et al. [5] reported that there was a significant difference in the minimum thickness of the distal root wall of the mesiobuccal (MB) canal of MFMs $2 \mathrm{~mm}$ below the furcation between long root teeth and short root teeth. The thinnest walls and the deepest concavities in the distal walls of the MRs were found in the longest teeth. Therefore, they suggest that long molars may have a higher risk of strip perforation in $\mathrm{MB}$ canals if flared to a larger size [5]. Dwivedi et al. [14] also reported that the distal wall thickness and distal concavity of the MRs of the MFMs were found to be thinner in longer teeth compared with shorter teeth, with the difference approximate $0.8 \mathrm{~mm}$. However, although the thickness of the dentine in the danger zone has been studied widely, there are little information in the literatures correlating these measurements with other features of the teeth, such as patient's age and gender.

Many kinds of methods have been used to assess the minimum dentine thickness of danger zone, such as radiographs, serial sectioning [5, 7], Microcomputed tomographic (Micro-CT) [12]. Radiographs were not a reliable method for measuring residual thickness of tooth walls, because they showed greater thicknesses than were actually present [15]. Serial sectioning is destructive, so it can't be used in vivo and the samples can't be used for further studies. MicroCT provide detailed information about the dentine thicknesses, canal morphology and curvatures in micrometer intervals [12]. It with novel software also provide valuable anatomical information for optimizing instrumentation and minimizing mishaps in nonsurgical root canal treatment [16]. However, Micro-CT has high radiation doses and limited specimen size, it could not be used to scan the head of a living human, which limits its clinic application. Cone-beam computed tomographic (CBCT) imaging provides high-quality, accurate, nondestructive 3dimensional system for proper information and identification of internal root canal anatomy [17]. It can be a powerful tool in endodontic diagnosis, treatment planning and follow-up [18]. СВCT imaging could measure dentine thickness accurately [19]. Therefore, the aim of this study was to assess the minimum distal dentine thickness of danger zone using CBCT and to analyze the correlation between the dentine thickness and root length, age and gender, side of the MFMs in Chinese population.

\section{Methods}

\section{CBCT images collections}

The Ethical Committee Department of the Affiliated Stomatological Hospital of Nanjing Medical University approval was obtained (PJ2017-053-001). Written informed consents were acquired from all patients. CBCT images scanned for endodontic, orthodontic or implant treatment, diagnosis of impacted teeth and facial trauma were randomly collected from the Department of Radiology, the Affiliated Stomatological Hospital of Nanjing Medical University from Aug 2017 to Dec 2018. The CBCT images showed the MFMs clearly. The samples were selected according to the following exclusion criteria: (1) MFMs with unformed apices, root resorption or fractures. (2) MFMs with complicated root canal morphology or calcification that root canals cannot be identified clearly. (3) The presence of caries, periapical or periradicular lesions, or any other odontogenic or nonodontogenic pathology. (4) MFMs treated by root canal filling, posts or crowns restoration. (5) Artifacts from adjacent implants or metal crowns which made the measurement can't be carried out.

CBCT images of 1792 MFMs from 898 individuals (445 men and 453 women) were selected. The age of the patients ranged from 18 to 89 years, with mean age of $43.39 \pm 13.96$ years for men and $40.14 \pm 14.00$ years for women. The patients were stratified into 3 categories: $18-30$ years group, $31-50$ years group and $\geq 51$ years group.

\section{CBCT images evaluations}

MFMs were imaged with a CBCT scanner (NewTom VG, QR srl., Verona, Italy) at $110 \mathrm{kVp}$ and $3.6 \sim 4.8 \mathrm{~mA}$ with a voxel size of $0.2 \mathrm{~mm}$ and field of view of $12 \times 8$ $\mathrm{cm}$ or $15 \times 15 \mathrm{~cm}$ by an experienced radiologist according to the manufacturer's recommended protocol.

Images were assessed by two experienced endodontists using NNT 4.6 software (QR srl., Verona, Italy), which can adjust the contrast and brightness to achieve optimal visualization. Before the experimental reading, their measurements were calibrated by reviewing $20 \mathrm{CBCT}$ images of MFMs selected to ensure the veracity of the values. The intra and inter-examiner reliability were assessed by Cohen's kappa statistical analysis. The kappa values for the intra-examiner and inter-examiner agreements were 0.877 to 0.933 , respectively.

The MR length of each specimen was recorded from the furcation of MFMs to the apex using CBCT axial planes, and categorized according to the length of teeth as follows: long root $(>10.0 \mathrm{~mm})$, medium root $(9.0 \sim 10$ $\mathrm{mm})$, short root $(<9.0 \mathrm{~mm})$. The minimum distal wall thickness of the MB and mesiolingual (ML) canals were measured according to previous studies [20]. Briefly, 1, $2,3,4,5 \mathrm{~mm}$ under the furcation, the minimum distal 


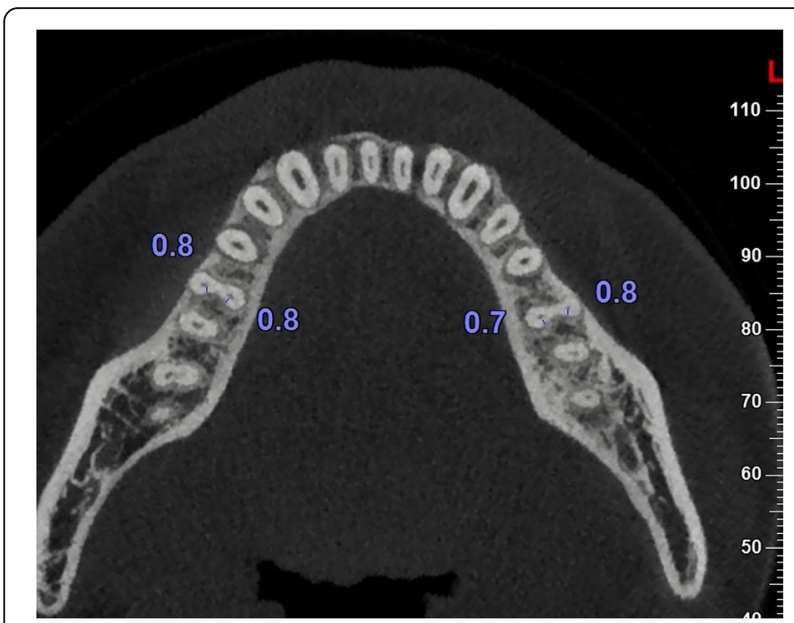

Fig. 1 Measurement of the minimum distal dentine thickness of danger zone on CBCT images

wall thickness of the MB and ML canals of the MRs was measured in axial planes by measuring the minimum distance from the edge of the root canal to the external surface of the root distal concavity (Fig. 1). All measurements were performed at 4 magnifications using the NNT software. The thickness was measured three times, and the mean thickness was recorded.

\section{Statistical analysis}

The association between the minimum distal wall thickness and the root length, patient's age and gender, side were assessed using the Wilcoxon and the KruskalWallis test with the SPSS 22.0 (IBM Corp., Armonk, NY, USA). $P<0.05$ was considered statistically significant.

\section{Results}

Association between the minimum distal dentine thickness and the patient's age and gender

The association between the minimum distal dentine thickness of $\mathrm{MB}$ and $\mathrm{ML}$ canals and the patient's age and gender are showed in Tables 1 and 2.

The minimal distal dentine thicknesses of MB and ML canals are located $3 \sim 4 \mathrm{~mm}$ below the furcation for both men and women. There are no differences between MB and ML canals, while the minimal distal dentine thicknesses of $\mathrm{MB}$ and ML canals were higher in men than women $(P<0.05)$, except at 1 and $3 \mathrm{~mm}$ of ML canals $(P>0.05)$.

The minimal distal dentine thicknesses of $\mathrm{MB}$ and $\mathrm{ML}$ canals increased with age in every age group in both men and women at each location $(P<0.05)$.

\section{Association between the minimum distal dentin thickness and the root lengths}

The association between the minimum distal dentine thickness and the root lengths are showed in Table 3. The minimum distal dentine thickness at every location was significantly different between long teeth and short teeth both in men and women $(P<0.05)$, with short teeth being smallest.

\section{Association between the minimum distal dentine thickness and side}

At every location, there are no significant differences between right and left side MFMs $(P>0.05)$ (Table 4).

\section{Discussion}

Root and canal morphology of permanent teeth showed close associations with age and gender [21, 22]. The pulp-dentinal complex change over the course of a lifetime with physiological deposition of secondary dentine, which contributing to a reduction of the pulp chamber size and root canal diameter [23, 24]. Consequently, canals were sharply defined and narrow, sometimes too narrow in older adults, while young patients tend to have large single canals and pulp chambers [23]. In addition, the cementum deposition with time in people and peaks in old age, resulting in a complex and changeful root morphology in old age [25]. Therefore, it is accepted that calcific changes of the pulp-dentinal complex over time pose challenges for the clinician [26].

The dangerous zone of the root canal preparation is the weakest thickness zone of the root canal wall. Root thickness tends to decrease considerably in danger zone during root canal shaping. It is particularly prone to excessive weakness and undesirable side effects [10], especially Nickel-titanium (NiTi) instruments are extensively used in endodontic treatment [27]. Stress concentration of tooth root should be concerned during the dental treatment, because it is closely related to vertical root fracture. In term of stress concentration, canal curvature

Table 1 The minimal distal dentine thicknesses of MB canals in danger zone (mean \pm SD, mm)

\begin{tabular}{|c|c|c|c|c|c|c|c|c|c|c|}
\hline \multirow[t]{2}{*}{ Groups } & \multicolumn{5}{|l|}{ Men } & \multicolumn{5}{|l|}{ Women } \\
\hline & $1 \mathrm{~mm}$ & $2 \mathrm{~mm}$ & $3 \mathrm{~mm}$ & $4 \mathrm{~mm}$ & $5 \mathrm{~mm}$ & $1 \mathrm{~mm}$ & $2 \mathrm{~mm}$ & $3 \mathrm{~mm}$ & $4 \mathrm{~mm}$ & $5 \mathrm{~mm}$ \\
\hline $18-30 y$ & $0.95 \pm 0.15$ & $0.80 \pm 0.14$ & $0.78 \pm 0.13$ & $0.80 \pm 0.14$ & $0.78 \pm 0.14$ & $0.89 \pm 0.14$ & $0.76 \pm 0.14$ & $0.74 \pm 0.13$ & $0.76 \pm 0.14$ & $0.76 \pm 0.15$ \\
\hline $31-50$ y & $0.96 \pm 0.17$ & $0.82 \pm 0.15$ & $0.80 \pm 0.14$ & $0.79 \pm 0.14$ & $0.81 \pm 0.13$ & $0.93 \pm 0.16$ & $0.79 \pm 0.14$ & $0.79 \pm 0.13$ & $0.80 \pm 0.14$ & 0.14 \\
\hline$\geq 51 \mathrm{y}$ & $1.01 \pm 0.18$ & $0.85 \pm 0.15$ & $0.82 \pm 0.15$ & $0.83 \pm 0.15$ & $0.83 \pm 0.15$ & $0.97 \pm 0.16$ & $0.84 \pm 0.14$ & $0.81 \pm 0.14$ & $0.81 \pm 0.15$ & $0.82 \pm 0.14$ \\
\hline Total & $0.98 \pm 0.17$ & $0.83 \pm 0.15$ & $0.80 \pm 0.14$ & $0.81 \pm 0.14$ & $0.81 \pm 0.14$ & $0.93 \pm 0.16$ & $0.79 \pm 0.14$ & $0.78 \pm 0.14$ & $0.79 \pm 0.14$ & $0.79 \pm 0.13$ \\
\hline
\end{tabular}


Table 2 The minimal distal dentine thicknesses of $M L$ canals in danger zone (mean $\pm S D, m m$ )

\begin{tabular}{|c|c|c|c|c|c|c|c|c|c|c|}
\hline \multirow[t]{2}{*}{ Groups } & \multicolumn{5}{|l|}{ Men } & \multicolumn{5}{|l|}{ Women } \\
\hline & $1 \mathrm{~mm}$ & $2 \mathrm{~mm}$ & $3 \mathrm{~mm}$ & $4 \mathrm{~mm}$ & $5 \mathrm{~mm}$ & $1 \mathrm{~mm}$ & $2 \mathrm{~mm}$ & $3 \mathrm{~mm}$ & $4 \mathrm{~mm}$ & $5 \mathrm{~mm}$ \\
\hline $18-30$ y & $0.98 \pm 0.14$ & $0.82 \pm 0.13$ & $0.79 \pm 0.12$ & $0.79 \pm 0.13$ & $0.80 \pm 0.10$ & $0.98 \pm 0.16$ & $0.80 \pm 0.12$ & $0.77 \pm 0.12$ & $0.77 \pm 0.13$ & $0.78 \pm 0.13$ \\
\hline $31-50$ y & $1.00 \pm 0.17$ & $0.84 \pm 0$ & $0.79 \pm 0.13$ & $0.79 \pm 0.12$ & $0.80 \pm 0.13$ & $0.99 \pm 0.17$ & $0.82 \pm 0.14$ & $0.80 \pm 0.13$ & $0.79 \pm 0.12$ & $0.80 \pm 0.13$ \\
\hline $51-60$ y & $1.02 \pm 0.17$ & $0.86 \pm 0.15$ & $0.82 \pm 0.14$ & $0.82 \pm 0.13$ & $0.83 \pm 0.12$ & $1.02 \pm 0.17$ & $0.84 \pm 0.14$ & $0.81 \pm 0.13$ & $0.82 \pm 0.14$ & $0.82 \pm 0.13$ \\
\hline Total & $1.01 \pm 0.17$ & $0.84 \pm 0.15$ & $0.80 \pm 0.13$ & $0.80 \pm 0.13$ & $0.81 \pm 0.12$ & $0.99 \pm 0.17$ & $0.82 \pm 0.13$ & $0.79 \pm 0.13$ & $0.79 \pm 0.13$ & $0.80 \pm 0.13$ \\
\hline
\end{tabular}

seems more important than external root morphology, and that reduced dentine thickness increases the magnitude but not the direction of maximum tensile stress [28]. Versluis et al. [29] reported that external distal and mesial surfaces of roots with oval canals showed moderate stress concentrations that were minimally affected by preparations, while stress concentrations emerged on roots with round canals when preparation sizes increased. Therefore, better understanding of the danger zone anatomy may serve to decrease the risk of mishaps.

There are some reports on the radicular wall thicknesses of danger zone in MFMs, which showed that the mean thickness of dentin ranges from 0.78 to $1.27 \mathrm{~mm}$, with the minimal thicknesses of $0.4 \mathrm{~mm}[3,7,9-11,13$, 30]. For example, Bryant et al. [31] reported that the mean size of the danger zone for 200 canals used was $0.79 \mathrm{~mm}$. Keles et al. [32] reported that the thinnest canal walls of $\mathrm{MB}$ canals were $1.16 \pm 0.20 \mathrm{~mm}$ and $\mathrm{ML}$ canals were $1.19 \pm 0.18 \mathrm{~mm}$. De-Deus et al. [33] found that the danger zone values in the $\mathrm{MB}$ canals varied from 0.67 to $1.93 \mathrm{~mm}$ with an average of $1.13 \pm 0.21 \mathrm{~mm}$, and in the ML canals varied from 0.77 to $1.89 \mathrm{~mm}$ with an average of $1.10 \pm 0.21 \mathrm{~mm}$, locating up to $4 \mathrm{~mm}$ under the furcation area. These results vary slightly because the researchers had used different methods of measuring the thickness of the root canal wall in the danger zone, and they selected different ranges of the danger zone or different human species for studies. Moreover, there is little information in the literatures correlating these measurements with other features of the teeth, such as patient's age and gender.

In the present study, the minimal distal dentine thicknesses associated with the MB and ML canals below the furcation 1, 2, 3, 4, $5 \mathrm{~mm}$ of Chinese population were measured. The results showed that the minimal distal dentine thicknesses of MB and ML canals are located $3 \sim 4 \mathrm{~mm}$ below the furcation for both men and women, with a mean range of $0.78 \sim 0.80$ $\mathrm{mm}$, and there are no differences between $\mathrm{MB}$ and ML canals. The result indicated that the danger zone of MFMs is located at the same position for both men and women.

In the present study, the minimal distal dentine thicknesses of $\mathrm{MB}$ and $\mathrm{ML}$ canals were higher in men than women $(P<0.05)$, except at 1 and $3 \mathrm{~mm}$ of $\mathrm{ML}$ canals $(P>0.05)$. These results confirm that the minimal distal dentine thicknesses of MB and ML canals with differs between men and women. Gender is an important factor to influence the distal wall thickness of the MRs of the MFMs. MFMs of women are more probability to strip perforation during root canal shaping and post space preparation procedures. Therefore, thinner or smaller instruments are suitable for women during endodontic treatment and post space preparation procedures.

The results of this study showed that the minimal distal dentine thicknesses of MB and ML canals increased with age in every age group in both men and women at each location $(P<0.05)$. Age is another important factor to influence the distal wall thickness of the MRs of the MFMs. MFMs of younger people have larger canals and thinner root canal walls than these of older people.

The results of this study showed that the minimum distal dentine thickness at every location was significantly different between long teeth and short teeth both in men and women $(P<0.05)$, with short teeth being smallest. These results are different with previous reports by Sauáia et al. [5] and Dwivedi et al. [14] in which the distal wall thickness and distal concavity of the MRs of the MFMs were found to be thinner in longer teeth compared with shorter teeth. Possible explanation is that ethnic difference is an important factor to influence the distal wall thickness of the MR of the MFMs.

Table 3 The minimal distal dentine thicknesses of mesial roots in danger zone according to root lengths (mean \pm SD, mm)

\begin{tabular}{|c|c|c|c|c|c|c|c|c|c|c|}
\hline \multirow[t]{2}{*}{ Groups } & \multicolumn{5}{|l|}{ Men } & \multicolumn{5}{|l|}{ Women } \\
\hline & $1 \mathrm{~mm}$ & $2 \mathrm{~mm}$ & $3 \mathrm{~mm}$ & $4 \mathrm{~mm}$ & $5 \mathrm{~mm}$ & $1 \mathrm{~mm}$ & $2 \mathrm{~mm}$ & $3 \mathrm{~mm}$ & $4 \mathrm{~mm}$ & $5 \mathrm{~mm}$ \\
\hline long & $0.97 \pm 0.17$ & $0.82 \pm 0.13$ & $0.78 \pm 0.12$ & $0.78 \pm 0.11$ & $0.78 \pm 0.11$ & $0.97 \pm 0.16$ & $0.82 \pm 0.13$ & $0.79 \pm 0.14$ & $0.82 \pm 0.14$ & $0.82 \pm 0.12$ \\
\hline medium & $0.93 \pm 0.15$ & $0.79 \pm 0.13$ & $0.76 \pm 0.12$ & $0.76 \pm 0.12$ & $0.78 \pm 0.11$ & $0.91 \pm 0.14$ & $0.77 \pm 0.12$ & $0.75 \pm 0.11$ & $0.75 \pm 0.12$ & $0.76 \pm 0.12$ \\
\hline short & $0.92 \pm 0.14$ & $0.76 \pm 0.13$ & $0.74 \pm 0.11$ & $0.75 \pm 0.12$ & $0.75 \pm 0.11$ & $0.87 \pm 0.13$ & $0.73 \pm 0.13$ & $0.71 \pm 0.11$ & $0.73 \pm 0.11$ & $0.74 \pm 0.12$ \\
\hline
\end{tabular}


Table 4 The minimal distal dentine thicknesses of mesial roots in danger zone according to side ( $m e a n \pm S D, m m$ )

\begin{tabular}{|c|c|c|c|c|c|c|c|c|c|c|}
\hline \multirow[t]{2}{*}{ Groups } & \multicolumn{5}{|l|}{ Men } & \multicolumn{5}{|l|}{ Women } \\
\hline & $1 \mathrm{~mm}$ & $2 \mathrm{~mm}$ & $3 \mathrm{~mm}$ & $4 \mathrm{~mm}$ & $5 \mathrm{~mm}$ & $1 \mathrm{~mm}$ & $2 \mathrm{~mm}$ & $3 \mathrm{~mm}$ & $4 \mathrm{~mm}$ & $5 \mathrm{~mm}$ \\
\hline Left & $0.94 \pm 0.15$ & $0.78 \pm 0.13$ & $0.76 \pm 0.12$ & $0.76 \pm 0.12$ & $0.77 \pm 0.11$ & $0.90 \pm 0.15$ & $0.76 \pm 0.13$ & $0.74 \pm 0.13$ & $0.75 \pm 0.12$ & $0.76 \pm 0.12$ \\
\hline Right & $0.94 \pm 0.15$ & $0.80 \pm 0.13$ & $0.76 \pm 0.11$ & $0.76 \pm 0.12$ & $0.78 \pm 0.11$ & $0.91 \pm 0.14$ & $0.76 \pm 0.12$ & $0.74 \pm 0.11$ & $0.76 \pm 0.12$ & $0.76 \pm 0.12$ \\
\hline
\end{tabular}

The decrease of the dentine thickness is an important point during the evaluation of root canal instrumentation because excessive enlargement of the root canal space can lead to accidents such as perforations. According to Lim and Stock, 200 300 $\mu \mathrm{m}$ dentine thickness should be retained after preparation in order to withstand compaction forces during obturation and to prevent perforation or vertical root fracture [13]. Based on the results of the present study, root canal preparation in danger zone decrease dentine should not more than $0.5 \mathrm{~mm}$, otherwise the possibility of perforation increases. To prevent strip perforations, firstly, the selection of great taper NiTi instruments should be cautious for the "danger zone" of insufficient dentin thickness of root canal wall. Secondly, coronal flaring should be limited and instruments should be directed towards the lateral and mesial canal walls that have much thicker dentine and away from the danger zone [9]. Finally, dentists should pay more attention to shorter teeth of young women during endodontic treatment and post space preparation procedures.

This study provided a detailed description of the distal wall thickness of the MRs of the MFMs in a large sample of a Chinese population. These findings are very important for clinicians because they will help to increase the success rates for endodontic treatment and post space preparation of patients of different gender and ages. In the study, some middle mesial canals (MMCs) of MRs were found in MFMs. However, due to the small number of MMCs in every age group, no measurements were made. In addition, the danger zone was mainly towards the distal region of the roots and towards the mesial region in few MB and ML canals, so the mesial wall thickness was not measured. Further studies will be conducted to investigate these issues.

\section{Conclusions}

Under the limitations of the present study, it may be concluded that the minimal distal dentine thicknesses of MRs in MFMs were higher in men than women, and increased as age advances both in men and women. In addition, the minimal distal dentine thicknesses of MRs in shorter MFMs is thinner than in longer teeth. These results suggested that the use of large taper instruments should be careful to prevent root canal perforation and other complications in patients who are younger or have shorter root lengths, especially in female patients.

\section{Abbreviations}

CBCT: Cone-beam computed tomography; MB: Mesiobuccal; MFMs: Mandibular first molars; Micro-CT: Micro-computed tomographic; ML: Mesiolingual; MMCs: Middle mesial canals; MRs: Mesial roots; NiTi: Nickeltitanium

\section{Acknowledgements}

We wish to thank Shengquan Han for his support in data statistical analysis.

\section{Authors' contributions}

All authors made substantial contributions to the present study. GZ and DL contributed to acquisition of data, data analysis, writing the paper. ML, YZ, CZ and CS contributed to CBCT images collection, evaluation and data analysis. DW contributed to the study design, interpretation of the results, writing the paper, supervision. All authors have read and approved the final manuscript.

\section{Funding}

This work was supported by the Scientific Research of Jiangsu Commission of Health (H2017050). The funding body had no role in the design of the study, the collection, analysis and interpretation of data or in the writing of the manuscript.

\section{Availability of data and materials}

The datasets used and/or analysed during the current study are available from the corresponding author on reasonable request.

\section{Ethics approval and consent to participate}

This study was approved by the Ethical Committee Department, the Affiliated Stomatological Hospital of Nanjing Medical University (PJ2017-053001). Written informed consents were obtained from all participants.

\section{Consent for publication}

Not applicable.

\section{Competing interests}

The authors declare that they have no competing interests.

\section{Author details}

'Jiangsu Key Laboratory of Oral Diseases, Nanjing Medical University, 136 Hanzhong Road, Nanjing 210029, People's Republic of China. 'Department of Radiology, the Affiliated Stomatological Hospital of Nanjing Medical University, 136 Hanzhong Road, Nanjing 210029, People's Republic of China. ${ }^{3}$ Department of Endodontics, the Affiliated Stomatological Hospital of Nanjing Medical University, 136 Hanzhong Road, Nanjing 210029, People's Republic of China.

Received: 22 May 2019 Accepted: 29 January 2020

Published online: 06 February 2020

\section{References}

1. Hull TE, Robertson PB, Steiner JC, del Aguila MA. Patterns of endodontic care for a Washington state population. J Endod. 2003;29:553-6.

2. Akbarzadeh $N$, Aminoshariae $A$, Khalighinejad NA, et al. The association between the anatomic landmarks of the pulp chamber floor and the prevalence of middle mesial canals mandibular first molars: an in vivo analysis. J Endod. 2017;43:1797-801.

3. Berutti $E_{1}$ Fedon $G$. Thickness of cementum/dentin in mesial roots of mandibular first molars. J Endod. 1992;18:545-8.

4. Abou-Rass M, Frank AL, Glick DH. The anticurvature filing method to prepare the curved root canal. J Am Dent Assoc. 1980;101:792-4. 
5. Saua'ia TS, BPFA G, Pinheiro ET, et al. Thickness of dentine in mesial roots of mandibular molars with different lengths. Int Endod J. 2010;43:555-9.

6. Eghbal MJ, Fazlyab M, Asgary S. Repair of a strip perforation with calciumenriched mixture cement: a case report. Iran Endod J. 2014;9:225-8.

7. Tabrizizadeh M, Reuben J, Khalesi M, et al. Evaluation of radicular dentin thickness of danger zone in mandibular first molars. J Dent (Tehran). 2010;7:196-9.

8. Olivier JG, García-Font M, Gonzalez-Sanchez JA, Roig-Cayon M, DuránSindreu F. Danger zone analysis using cone beam computed tomography after apical enlargement with K3 and K3XF in a manikin model. J Clin Exp Dent. 2016;8:e361-7.

9. Garcia Filho PF, Letra A, Menezes R, Carmo AM. Danger zone in mandibular molars before instrumentation: an in vitro study. J Appl Oral Sci. 2003;11:324-6.

10. Kessler JR, Peters DD, Lorton L. Comparison of the relative risk of molar root perforations using various endodontic instrumentation techniques. J Endod. 1983;9:439-47.

11. Montgomery S. Root canal wall thickness of mandibular molar after biomechanical preparation. J Endod. 1985;1:257-63.

12. Harris SP, Bowles WR, Fok A, McClanahan SB. An anatomic investigation of the mandibular first molar using micro-computed tomography. J Endod. 2013;39:1374-8

13. Lim SS, Stock CJ. The risk of perforation in the curved canal: anticurvature filling compared with step back technique. Int Endod J. 1987;20:33-9.

14. Dwivedi S, Dwivedi CD, Mittal N. Correlation of root dentin thickness and length of roots in mesial roots of mandibular molars. J Endod. 2014;40: $1435-8$.

15. Raiden G, Koss S, Costa L, et al. Radiographic measurement of residual root thickness in premolars with post preparation. J Endod. 2001;27:296-8.

16. Lee JK, Yoo YJ, Perinpanayagam $\mathrm{H}$, et al. Three-dimensional modelling and concurrent measurements of root anatomy in mandibular first molar mesial roots using micro-computed tomography. Int Endod J. 2015;48:380-9.

17. Gu Y, Sun C, Wu D, et al. Evaluation of the relationship between maxillary posterior teeth and the maxillary sinus floor using cone-beam computed tomography. BMC Oral Health. 2018;18:164.

18. Patel $\mathrm{S}$, Durack $\mathrm{C}$, Abella F, et al. Cone beam computed tomgraphy in endodontics- a review. Int Endod J. 2015;48:3-15.

19. Xu J, He J, Yang Q, et al. Accuracy of cone-beam computed tomography in measuring dentin thickness and its potential of predicting the remaining dentin thickness after removing fractured instruments. J Endod. 2017:43:1522-7.

20. Isom TL, Marshall JG, Baumgartner JC. Evaluation of root thickness in curved canals after flaring. J Endod. 1995;21:368-71.

21. Martins JNR, Ordinola-Zapata R, Marques D, Francisco H, Caramês J. Differences in root canal system configuration in human permanent teeth within different age groups. Int Endod J. 2018:51:931-41.

22. Sert S, Bayirli GS. Evaluation of the root canal configurations of the mandibular and maxillary permanent teeth by gender in the Turkish population. J Endod. 2004;30:391-8

23. Gani OA, Boiero CF, Correa C, et al. Morphological changes related to age in mesial root canals of permanent mandibular first molars. Acta Odontol Latinoam. 2014;27:105-9.

24. Reis AG, Grazziotin-Soares R, Barletta FB, et al. Second canal in mesiobuccal root of maxillary molars is correlated with root third and patient age: a cone-beam computed tomographic study. J Endod. 2013;39:588-92.

25. Wu D, Zhang G, Liang $R$, et al. Root and canal morphology of maxillary second molars by cone-beam computed tomography in a native Chinese population. J Inter Med Res. 2017:45:830-42.

26. Johnstone M, Parashos P. Endodontics and the ageing patient. Aus Dent J. 2015:60:20-7.

27. ElAyouti A, Dima E, Judenhofer MS, et al. Increased apical enlargement contributes to excessive dentin removal in curved root canals: a stepwise microcomputed tomography study. J Endod. 2011;37:1580-4.

28. Lertchirakarn V, Palamara JE, Messer HH. Patterns of vertical root fracture: factors affecting stress distribution in the root canal. J Endod. 2003;29(8):523-8.

29. Versluis A, Messer HH, Pintado MR. Changes in compaction stress distributions in roots resulting from canal preparation. Int Endod J. 2006; 39(12):931-9.

30. Leite Pinto SS, Lins RX, Videira Marceliano-Alves MF, et al. The internal anatomy of danger zone of mandibular molars: a cone-beam computed tomography study. J Conserv Dent. 2018;21(5):481-4.
31. Bryant ST, Dummer PM, Pitoni C, et al. Shaping ability of 0.04 and 0.06 taper profile rotary nickel-titanium instruments in stimulated root canals. Int Endod J. 1999:32:155-64.

32. Keles A, Keskin C, Alqawasmi R, et al. Evaluation of dentine thickness of middle mesial canals of mandibular molars prepared with rotary instruments: a micro-CT study. Int Endod J. 2019. https://doi.org/10. 1111/iej.13247.

33. De-Deus G, Rodrigues EA, Belladonna FG, et al. Anatomic danger zone reconsidered: a micro-CT study on dentine thickness in mandibular molars. Int Endod J. 2019;52(10):1501-7.

\section{Publisher's Note}

Springer Nature remains neutral with regard to jurisdictional claims in published maps and institutional affiliations.
Ready to submit your research? Choose BMC and benefit from:

- fast, convenient online submission

- thorough peer review by experienced researchers in your field

- rapid publication on acceptance

- support for research data, including large and complex data types

- gold Open Access which fosters wider collaboration and increased citations

- maximum visibility for your research: over $100 \mathrm{M}$ website views per year

At BMC, research is always in progress.

Learn more biomedcentral.com/submissions 